\title{
A micromethod for quantitation of debrisoquine and 4-hydroxydebrisoquine in urine by liquid chromatography
}

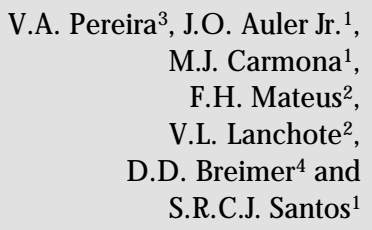

\section{Correspondence \\ S.R.C.J. Santos \\ Laboratório de Pesquisa Instituto do Coração, HC, FM, USP Av. Dr. Eneas C. de Aguiar, 44 05403-000 São Paulo, SP Brasil}

Research supported by FAPESP (No. 97/14466-7).

Received April 23, 1999 Accepted February 3, 2000

\author{
IInstituto do Coração, Faculdade de Medicina, Universidade de São Paulo, \\ São Paulo, SP, Brasil \\ ${ }^{2}$ Laboratório de Toxicologia, Faculdade de Ciências Farmacêuticas de Ribeirão Preto, \\ Universidade de São Paulo, Ribeirão Preto, SP, Brasil \\ ${ }^{3}$ Laboratório de Farmacologia Terapêutica, U nidade 2, Faculdade de Ciências \\ Farmacêuticas, Universidade de São Paulo, São Paulo, SP, Brasil \\ ${ }^{4}$ Leiden-Amsterdam Center for D rug Research, Leiden, Holland
}

\section{Abstract}

We describe a new simple, selective and sensitive micromethod based on HPLC and fluorescence detection to measure debrisoquine (D) and 4-hydroxydebrisoquine (4-OHD) in urine for the investigation of xenobiotic metabolism by debrisoquine hydroxylase (CYP2D6). Four hundred $\mu \mathrm{l}$ of urine was required for the analysis of D and 4-OHD. Peaks were eluted at $8.3 \mathrm{~min}$ (4-OHD), $14.0 \mathrm{~min}$ (D) and $16.6 \mathrm{~min}$ for the internal standard, metoprolol $(20 \mu \mathrm{g} / \mathrm{ml})$. The $5-\mu \mathrm{m}$ CN-reversephase column (Shimpack, $250 \times 4.6 \mathrm{~mm}$ ) was eluted with a mobile phase consisting of $0.25 \mathrm{M}$ acetate buffer, $\mathrm{pH} 5.0$, and acetonitrile $(9: 1, \mathrm{v} / \mathrm{v})$ at $0.7 \mathrm{ml} / \mathrm{min}$ with detection at $\lambda_{\text {excitation }}=210 \mathrm{~nm}$ and $\lambda_{\text {emission }}$ $=290 \mathrm{~nm}$. The method, validated on the basis of measurements of spiked urine, presented $3 \mathrm{ng} / \mathrm{ml}$ (D) and $6 \mathrm{ng} / \mathrm{ml}$ (4-OHD) sensitivity, 390-6240 ng/ml (D) and 750-12000 ng/ml (4-OHD) linearity, and 5.7/ $8.2 \%$ (D) and 5.3/8.2\% (4-OHD) intra/interassay precision. The method was validated using urine of a healthy Caucasian volunteer who received one 10-mg tablet of Declinax ${ }^{\circledR}$, po, in the morning after an overnight fast. Urine samples (diuresis of 4 or $6 \mathrm{~h}$ ) were collected from zero to $24 \mathrm{~h}$. The urinary excretion of D and 4-OHD, Fel (0-24 h), i.e., fraction of dose administered and excreted into urine, was $6.4 \%$ and $31.9 \%$, respectively. The hydroxylation capacity index reported as metabolic ratio was 0.18 (D/4-OHD) for the person investigated and can be compared to reference limits of $>12.5$ for poor metabolizers (PM) and $<12.5$ for extensive metabolizers (EM). In parallel, the recovery ratio (RR), another hydroxylation capacity index, was 0.85 (4-OHD: $\Sigma \mathrm{D}+4-\mathrm{OHD}$ ) versus reference limits of $\mathrm{RR}<0.12$ for PM and $R R>0.12$ for EM. The healthy volunteer was considered to be an extensive metabolizer on the basis of the debrisoquine test.

\section{Key words}

- Debrisoquine

- 4-Hydroxydebrisoquine

- HPLC-F

- U rinary excretion kinetics

- Debrisoquine test validation

- CYP2D 6
A series of drugs commonly prescribed for the treatment of cardiac patients have been identified as substrates of the CYP superfamilies I, II or III. Debrisoquine (D) hydroxylase, CYP2D6, an enzyme of super- family II, is responsible for alicyclic acid hydroxylation in the oxidative metabolism of many drugs used for cardiovascular therapy. The in vivo activity of CYP2D6 can be estimated by the debrisoquine test (1) 
after a single $p o$ dose of Declinax ${ }^{\circledR}$, a known antihypertensive agent commercialized by Roche (Produtos Roche Químicos e Farmacêuticos S.A., São Paulo, SP, Brazil) which contains $10 \mathrm{mg}$ debrisoquine sulfate per tablet. The measurement of CYP2D6 activity involves urine collection and simultaneous analysis and determination of D and 4hydroxydebrisoquine (4-OHD). The high sensitivity required, of the order of nanograms per milliliter of urine, requires the use of specific and sensitive methods.

Several sophisticated and high cost chromatographic methods involving gas chromatography with a flame ionization detector (2), a nitrogen-phosphorous flame ionization detector $(2,3)$ and a mass spectrometer detector (4) have been proposed but a series of difficulties were detected in their application to routine phenotyping. Liquid chromatography techniques using an ultraviolet detector have been reported $(3,5-8)$. However, the low sensitivity of UV detection requires pre- or post-column derivatization procedures.

Since only a fluorescence detector can provide sufficient sensitivity without requiring derivatization, the objective of the present study was to develop a simple, rapid and sensitive fluorimetric method for the simultaneous determination of $\mathrm{D}$ and 4-OHD in urine for routine population phenotyping.

All reagents and organic solvents, analytical or chromatography grade, were purchased from Sigma Chemical Company (St. Louis, MO, USA), EM Science (Gibbstown, NJ, USA), Merck (Darmstadt, Germany) and Grupo Química (Penha, RJ, Brazil). Sodium chloride, sodium hydroxide and sodium acetate (Sigma), acetonitrile and AXO142-1 (EM Science), dichlormethane and LiChrosolv 6044 (Merck), and isopropanol (UV-HPLC 03008) (Grupo Química) were necessary for the procedure. The nitrogen (ONU1066) used for solvent evaporation in the organic extracts and the helium (ONU1046) used to degas the mobile phase of chromatography,
99.99\% purity, were purchased from IBG Indústria Brasileira de Gases Ltda. (Jundiaí, SP, Brazil). A type HA 45 membrane was used for buffer filtration and a type FHLP45 membrane was used for filtration of the mobile phase and of the organic extracts (Millipore Corporation, Bedford, MA, USA).

The reference standard, debrisoquine sulfate, was donated by Roche and the 4hydroxydebrisoquine standard was kindly provided by Professor Sompon Wanwimolruk (Department of Pharmacy and MRC Toxicology Research Unit, University of Otago Medical School, Dunedin, New Zealand).

Ultrapure water was obtained using the MILLIQ ${ }^{\circledR}$ MILLIRO $^{\circledR}$ systems (Millipore Corporation) and was used to prepare the buffer solution of the mobile phase of chromatography and to clean and regenerate the liquid chromatography apparatus (Shimadzu Corporation, Tokyo, Japan).

Debrisoquine was determined in urine samples by high performance liquid chromatography using a Shimadzu LC-10AS apparatus equipped with an RF-10AXL fluorescence detector and connected to a model 7125 Rheodyne $^{\circledR}$ injector with a $50 \mu 1$ loop, a Nova-Pak ${ }^{\circledR}$ CN Guard-Pak ${ }^{\mathrm{TM}}$ HPLC precolumn insert (Waters Corporation, Milford, CT, USA) and a Shimpack ${ }^{\circledR}$ CLC-CN Shimadzu column, $250 \times 4.6 \mathrm{~mm}$ ID, $5 \mu \mathrm{m}$. The mobile phase consisted of $0.25 \mathrm{M}$ acetate buffer, $\mathrm{pH} 5.0$, and acetonitrile $(9: 1, \mathrm{v} / \mathrm{v}$, final $\mathrm{pH}=5.4$ ) in an isocratic elution system at a flow rate of $0.7 \mathrm{ml} / \mathrm{min}$. The column effluent was monitored at $210 \mathrm{~nm}\left(\lambda_{\text {excitation }}\right)$ and $290 \mathrm{~nm}\left(\lambda_{\text {emission }}\right)$. The chromatograms were obtained with a Shimadzu C-R6A Chromatopac ${ }^{\circledR}$ printer-plotter, which provided the elution diagrams and peak integration.

Fifty $\mu 1$ metoprolol in methanol $(20 \mu \mathrm{g} /$ $\mathrm{ml}$ ), the internal standard, was added to a dry clean extraction tube, followed by evaporation in a water bath at $37^{\circ} \mathrm{C}$ under a nitrogen flow. Four hundred- $\mu l$ urine aliquots were 
used in duplicate both for calibration with reference standards and for the samples. The biological sample was purified by the addition of $80 \mathrm{mg}$ sodium chloride/assay, urine was alkalinized to $\mathrm{pH} 9.0$ by the addition of $50 \mu 10.4 \mathrm{M}$ sodium hydroxide $(20 \mu \mathrm{mol})$ and extraction was performed with a mixture of dichloromethane:isopropanol $(6: 4, \mathrm{v} / \mathrm{v})$ in a vortex type tube shaker for $1 \mathrm{~min}$. After extraction and centrifugation at $3000 \mathrm{rpm}$ for $10 \mathrm{~min}$, the aqueous phase was separated from the organic phase by aspiration and discarded. The tube containing the remaining organic phase was then immersed in liquid nitrogen for $10 \mathrm{~s}$. The organic extract was then transferred to a clean and dry conical tube. The extracts were concentrated to dryness in a water bath at $37^{\circ} \mathrm{C}$ under a nitrogen flow. The dried extract was then dissolved in $100 \mu \mathrm{l}$ of the mobile phase and $50 \mu \mathrm{l}$ was injected into the liquid chromatography apparatus.

Calibration curves were constructed by the addition of $100 \mu \mathrm{l}$ of $\mathrm{D}(150 \mu \mathrm{g} / \mathrm{ml}$ stock methanol solution) and $100 \mu \mathrm{l}$ of 4-OHD (300 $\mu \mathrm{g} / \mathrm{ml}$ stock aqueous solution) to a volumetric flask. Volume was completed with drug-free human urine up to $5 \mathrm{ml}$. The spiked urine was diluted serially to obtain concentrations of D of 390 to $3120 \mathrm{ng} / \mathrm{ml}$ and of 4-OHD in the $750-$ to $6000-\mathrm{ng} / \mathrm{ml}$ range. The standard calibration curve was prepared in duplicate and contained the internal standard (metoprolol, $1 \mu \mathrm{g} /$ assay).

We determined the absolute recovery of $\mathrm{D}(85 \pm 8 \%)$ and $4-\mathrm{OHD}(80 \pm 7 \%)$ by comparing the injection of purified urine extracts with direct injection of standards ( $\mathrm{N}$ $=8$ replicates for $\mathrm{D}$ and 4-OHD). Relative recoveries calculated on the basis of the internal standard were $83 \pm 5 \%$ (D) and $95 \pm$ 4\% (4-OHD). The detection limit was $3 \mathrm{ng} /$ $\mathrm{ml}(7.9 \%)$ and $6 \mathrm{ng} / \mathrm{ml}(8.0 \%)$ for $\mathrm{D}$ and $4-$ OHD, respectively. The quantification limits determined on the basis of the analysis of urine aliquots (10 replicates) were $12 \mathrm{ng} / \mathrm{ml}$ D (7.7\%) and $23 \mathrm{ng} / \mathrm{ml} 4-\mathrm{OHD}$ (7.6\%). The precision of the analytical procedure measured by quantitative analysis of the two compounds under study in urine aliquots (5 replicates) on the same day (intraday precision) was $5.7 / 5.3 \%$ for $\mathrm{D} / 4-\mathrm{OHD}$, and $8.2 \%$ for both $\mathrm{D}$ and 4-OHD in 5 replicates on five consecutive days (interday precision) (Table 1).

We evaluated the debrisoquine activity of a healthy adult volunteer, a 50-year-old Caucasian female, height $172 \mathrm{~cm}$, weight 60 $\mathrm{kg}$, and body surface area $1.70 \mathrm{~m}^{2}$, with normal hepatic, renal, endocrine and cardiac functions. The volunteer received detailed information about the procedures to be performed and gave written informed consent to participate in the study. The study protocol was approved by the Ethics Committee of the School Hospital under number 1414/ $98 / 109$. The volunteer then received a single po dose of Declinax ${ }^{\circledR}$, one tablet containing $10 \mathrm{mg}$ debrisoquine sulfate, in the morning after an overnight fast. Urine was then collected from 0 to $4 \mathrm{~h}$ during the $0-24 \mathrm{~h}$ interval after administration of the CYP2D6 marker drug for validation of the analytical method described earlier.

The chromatographic pattern of the purified urine extracts is illustrated in Figure 1A. Chromatography was carried out for about 20 min.

The high selectivity of the chromatographic system utilized, together with the use of the fluorescence detector (Figure 1A), provided high sensitivity despite the small urine volume used. The linearity obtained for D and 4-OHD (Figure 1B) guaranteed good precision, with high reproducibility of the results. The confidence limits of the analytical method of simultaneous determination of $\mathrm{D}$ and of its 4-OHD in urine are listed in Table 1.

Since the micromethod for the determination of D and 4-OHD by liquid chromatography proved to be selective, sensitive and precise, we validated it by the debrisoquine test applied to a healthy adult volunteer. 
The exponential decay of $\mathrm{D}$ and 4-OHD forms in urine is illustrated in Figure 1C by plotting the fraction of dose administered and excreted into urine (Fel) versus time of midpoint (Tmp) (9-11). It is important to emphasize that D and 4-OHD were excreted at a 1:4 molar ratio during the 24 -h period of investigation. The elimination rate constant for $\mathrm{D}$ in urine $(\mathrm{Ku})$, formation rate constant for 4-OHD (Kf) and their respective halflives $(t(1 / 2) B)$ were estimated by Fel versus Tmp, using a semilogarithmic plot, as follows: $0.133 / \mathrm{h}(\mathrm{Ku}), 0.119 / \mathrm{h}(\mathrm{Kf})$ and $5.2 \mathrm{~h}$ (D), $5.8 \mathrm{~h}$ (4-OHD) for the biological halflives.

On the basis of the data for accumulated

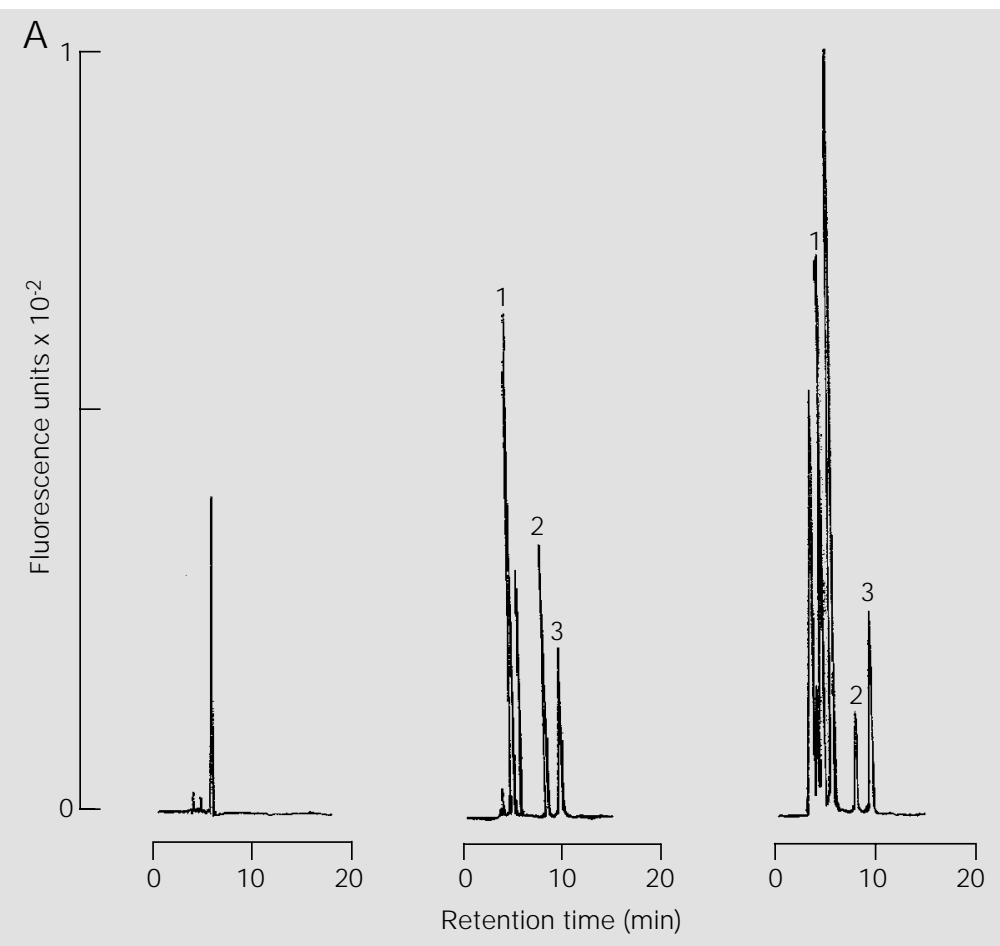

C

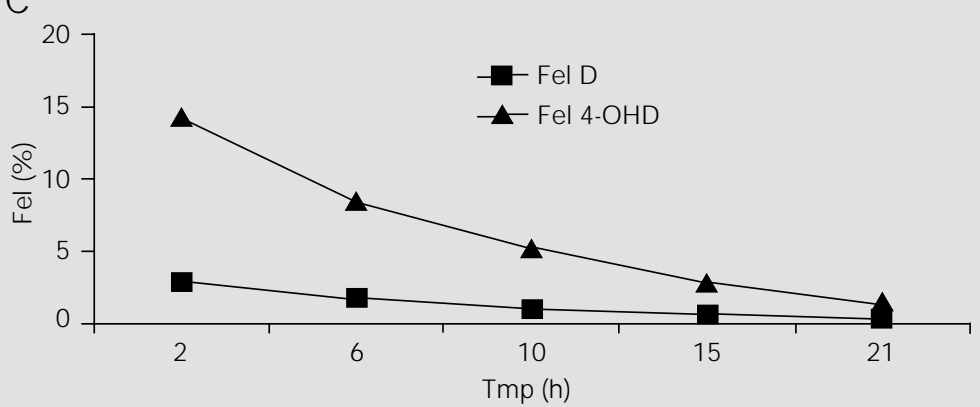

B
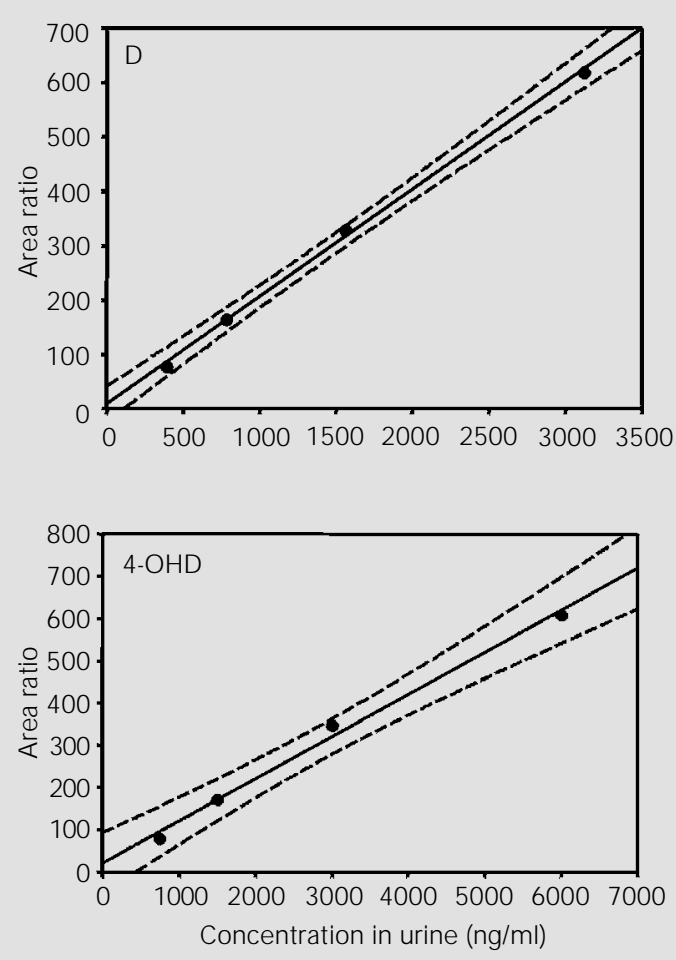

D

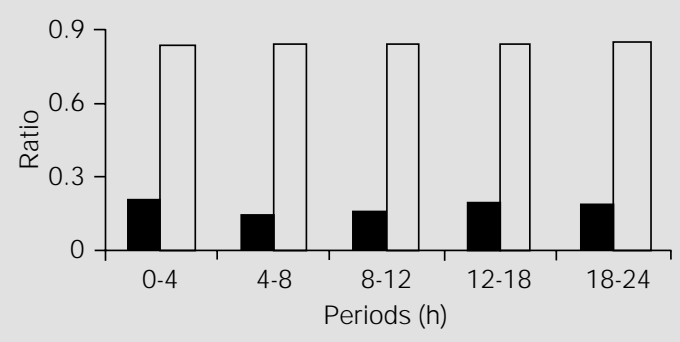

Figure 1 - A, Chromatographic pattern for the simultaneous determination of D and 4-OHD in urine by HPLC-F. Peaks: 1 - 4-OHD: 8.3 min, 300 ng; 2 - D: $14.0 \mathrm{~min}, 160 \mathrm{ng} ; 3$ - internal standard (metoprolol): $16.6 \mathrm{~min}, 8 \mu \mathrm{g}$. B, Calibration curves for D (upper) and 4-OHD (lower) peak area ratio versus concentration in urine. C, Exponential curve decay. Urinary excretion of debrisoquine (Fel D, squares) and of 4-hydroxydebrisoquine (Fel 4-OHD, triangles) versus time of midpoint (Tmp) after administration of the CYP2D6 marker drug to a healthy Caucasian volunteer. D, Ability to hydroxylate debrisoquine up to $24 \mathrm{~h}$ : metabolic ratio (closed bars) and recovery ratio (open bars) of diuresis (4- or 6-h intervals) for the healthy Caucasian volunteer investigated. 
fraction of dose administered and excreted into urine versus time, the following percentages were obtained for the D:4-OHD ratio: $2.9: 14.2 \%(0-4 \mathrm{~h}), 4.6: 22.6 \%(0-8 \mathrm{~h})$, $5.6: 27.8 \%(0-12 \mathrm{~h}), 6.2: 30.6 \%(0-18 \mathrm{~h})$, and $6.4: 31.9 \%(0-24 \mathrm{~h})$. It is interesting to observe that the total eliminated fraction (D + 4-OHD) ranged from 20 to $40 \%$ during the study period, as follows: $17.1 \%(0-4 \mathrm{~h})$, $27.2 \%(0-8 \mathrm{~h}), 33.4 \%$ (0-12 h), 36.8\% (0-18 $\mathrm{h})$, and $38.3 \%(0-24 \mathrm{~h})$.

The capacity for D hydroxylation measured on the basis of the recovery ratio (RR) that corresponds to the 4-OHD excretion in relation to the total eliminated (D + 4-OHD) yielded a value of 0.85 for the recovery ratio versus reference values of $R R>0.12$ and $R R$ $<0.12$ described previously for extensive metabolizers (EM) and poor metabolizers, (PM), respectively, for the $0-8$-h period (12). The patient studied is an EM since the value obtained was $0.85>0.12$. It should also be pointed out that the ratios were constant at all intervals from zero to $24 \mathrm{~h}$ as illustrated in Figure 1D.

When the capacity for D hydroxylation was measured on the basis of the metabolic ratio (MR) which corresponds to the excretion of $\mathrm{D}$ in relation to the metabolite eliminated, 4-OHD (1), the ratio obtained for the subject investigated was 0.18 versus reference values of MR $>12.5$ for $\mathrm{PM}$ and MR $<12.5$ for EM (Figure 1D). Therefore, this calculation confirmed the result obtained previously, since this was an EM.

The debrisoquine test based on 24-h urine collection (4 to $6 \mathrm{~h}$ diuresis) designed for this study protocol indicates that MR and RR, indexes of hydroxylation capacity, remained unchanged throughout the investigation. These findings indicate that urine collection can be simplified by reducing it to $8 \mathrm{~h}(0-4$, 4-8 $\mathrm{h}$ diuresis), allowing not only population phenotyping of hospitalized patients and outpatients, but also estimation of the kinetic parameters such as half-life and rate constants.
Table 1 - Confidence limits of the analytical method for simultaneous determination of debrisoquine and its hydroxylated metabolite by HPLC-F of urine.

(D:4-OHD) spiked blank of urine: low standard $(390: 750 \mathrm{ng} / \mathrm{ml})$, high standard (3120:6000 ng/ml). CV: Coefficient of variation; r: coefficient of linear correlation.

\begin{tabular}{|c|c|c|}
\hline Parameter & Debrisoquine & 4-Hydroxydebrisoquine \\
\hline $\begin{array}{l}\text { Linearity (ng/ml) } \\
\text { (CV\%) } \\
\text { Regression }\end{array}$ & $\begin{array}{c}390-6240 \\
(5.2 \%) \\
r=0.998\end{array}$ & $\begin{array}{c}750-12000 \\
(7.1 \%) \\
r=0.998\end{array}$ \\
\hline $\begin{array}{l}\text { Detection limit (ng/ml) } \\
\text { (CV\%) } \\
\text { Regression }\end{array}$ & $\begin{array}{c}3 \\
(7.9 \%) \\
r=0.903\end{array}$ & $\begin{array}{c}6 \\
(8.0 \%) \\
r=0.954\end{array}$ \\
\hline $\begin{array}{l}\text { Quantification limit (ng/ml) } \\
\text { (CV\%) } \\
\text { Regression }\end{array}$ & $\begin{array}{c}12 \\
(7.7 \%) \\
r=0.993\end{array}$ & $\begin{array}{c}23 \\
(7.6 \%) \\
r=0.992\end{array}$ \\
\hline $\begin{array}{l}\text { Recovery } \\
\text { absolute (\%) } \\
\text { relative }(\%)\end{array}$ & $\begin{array}{l}85 \pm 8 \\
83 \pm 5\end{array}$ & $\begin{array}{l}80 \pm 7 \\
95 \pm 4\end{array}$ \\
\hline Systematic error (\%) & 0.5 & 1.1 \\
\hline Interday precision (\%) & 8.2 & 8.2 \\
\hline $\begin{array}{l}\text { High standard (ng/ml) } \\
\text { (CV\%) } \\
\text { Low standard (ng/ml) } \\
\text { (CV\%) }\end{array}$ & $\begin{array}{c}3260 \pm 256 \\
(7.8 \%) \\
383 \pm 33 \\
(8.6 \%)\end{array}$ & $\begin{array}{c}6027 \pm 444 \\
(7.4 \%) \\
745 \pm 67 \\
(8.9 \%)\end{array}$ \\
\hline Intraday precision (\%) & 5.7 & 5.3 \\
\hline $\begin{array}{l}\text { High standard (ng/ml) } \\
\text { (CV\%) } \\
\text { Low standard (ng/ml) } \\
\text { (CV\%) }\end{array}$ & $\begin{array}{c}3204 \pm 177 \\
(5.5 \%) \\
391 \pm 23 \\
(5.9 \%)\end{array}$ & $\begin{array}{c}6170 \pm 352 \\
(5.7 \%) \\
749 \pm 36 \\
(4.8 \%)\end{array}$ \\
\hline
\end{tabular}

On the basis of the confidence intervals obtained in the present study and their validation by the application of the debrisoquine test to a healthy Caucasian volunteer (explained in detail above), we consider the proposed micromethod for simultaneous analysis to be sufficient for application to routine population phenotyping as an index of the capacity for hydroxylation through the measurement of CYP2D6 activity. This methodology has permitted the application of this test in studies currently carried out on high-risk surgical patients, guaranteeing the dose adjustment and the success of pharmacological therapy. Finally, MR and RR proved to be good indexes of the hydroxylation capacity of the enzyme, CYP2D6 for population phenotyping purposes. 


\section{Acknowledgments}

We are indebted to Roche (Produtos Roche Químicos e Farmacêuticos S.A.) for the reference standard, pure debrisoquine sulfate, and to Professor Sompon Wanwi- molruk (Department of Pharmacy and MRC Toxicology Research Unit, University of Otago Medical School, Dunedin, New Zealand) for the 4-hydroxydebrisoquine standard.

\section{References}

1. Evans DAP, Mahgoub A, Sloan TP, Idle J R \& Smith RL (1980). A family and population study of the genetic polymorphism of debrisoquine oxidation in a white British population. J ournal of Medical Genetics, 17: 102-105.

2. Lennard MS, Silas J H, Smith AJ \& Tucker GT (1977). Determination of debrisoquine and its 4-hydroxy metabolite in biological fluids by gas chromatography with flameionization and nitrogen-selective detection. J ournal of Chromatography, 133: 161-166.

3. Chan K (1988). Comparison of gas chromatographic and high-performance liquid chromatographic assays for the determination of debrisoquine and its 4-hydroxy metabolite in human fluids. J ournal of Chromatography. B, Biomedical Applications, 425: 311-321.

4. Daumas L, Sabot J F, Vermeulen E, Clapot P, Allegre F \& Pinatel H (1991). Determination of debrisoquine and metabolites in human urine by gas chromatography- mass spectrometry. J ournal of Chromatography. B, Biomedical Applications, 570: 89-97.

5. Duche J C, Barre J \& Tillement J P (1987). Rapid liquid chromatographic determination of debrisoquine and its hydroxy metabolite in human urine to define hydroxylation phenotypes. J ournal of Chromatography. B, Biomedical Applications, 423: 340-343.

6. J ohnson KA, Kolatkar V \& Straka RJ (1990). Improved selectivity of a high-performance liquid chromatography assay for debrisoquine and its 4-hydroxy metabolite from urine. Therapeutic Drug Monitoring, 12: 478-480.

7. MoncrieffJ (1988). Assay of debrisoquine and 4-hydroxydebrisoquine in urine by reversed-phase high-performance liquid chromatography using on-line sample clean-up on a standard isocratic chromatograph. J ournal of Chromatography. B, Biomedical Applications, 428: 178-182.

8. Wanwimolruk S \& Ferry DG (1990). Rapid high-performance liquid chromatographic method for the analysis of debrisoquine and 4-hydroxydebrisoquine in urine without derivatization. J oumal of Liquid Chromatography, 13: 961-968.

9. Gibaldi M (1991). Biopharmaceutics and Clinical Pharmacokinetics. 4th edn. Lea \& Febiger, Philadelphia, 203-233.

10. Shargel L \& Yu ABC (1999). Applied Biopharmaceutics \& Pharmacokinetics. 4th edn. Appleton \& Lange, Stamford, 325352.

11. Ritschel WA (1986). Handbook and Basic Pharmacokinetics. 2nd edn. Drug Intelligence Publications, Hamilton, 284-295.

12. Frye RF \& Branch RA (1996). Improved high-performance liquid chromatographic determination of debrisoquine and 4hydroxydebrisoquine in human urine following direct injection. J ournal of Chromatography. B, Biomedical Applications, 677: 178-182. 